\title{
Healthoare Burden of Extremely Preterm Birth and Prediotors of Hospital Length of Stay in the Netherlands
}

\author{
Sujata P. Sarda, ${ }^{1}$ Csaba Siffel, ${ }^{1}$ Jetty Overbeek, ${ }^{2}$ Eline Houben ${ }^{2}$ \\ 'Shire, Lexington, MA, USA; ${ }^{2}$ PHARMO Institute for Drug Outcomes Research, Utrecht, the Netherlands
}

\section{BACKGROUND}

Infants born before 28 weeks gestational age (GA), termed extremely preterm have long been recognised to have high rates of morbidity and mortality.

- Survival to discharge of extremely preterm infants has increased in developed countries due to advances in neonatal and maternal care practices such as antenatal corticosteroid use, less aggressive ventilation and strict infection control practices ${ }^{3-5}$

- This welcomed increase in survival has resulted in increased incidence of several comorbidities of prematurity and associated healthcare resource utilisation (HRU) and costs.

\section{OBJECTIVE}

The objectives were to characterise infant and maternal demographics, complications and procedures, HRU and direct costs associated with extremely preterm birth ( $<28$ weeks $G A)$

\section{METHODS}

\section{Study Design and Conduct}

A retrospective analysis of the PHARMO Database Network linked to the Netherlands Perinatal Registry (PRN) was conducted on infants with a birth record in the PRN and data in the PHARMO Out-patient Pharmacy and Hospitalisation Database.

- All patient data acquisition was fully compliant with rules governing the use of patient-level healthcare data in the Netherlands.

Analysis Population

- All preterm births (24-37 weeks GA) occurring from 1 January 1999 to 31 December 2015 without congenital malformations were selected.

- Eligible infants were followed from birth until transfer out of the database death or end of the study period (31 December 2016), whichever occurred first.

- The infants were divided into 4 subgroups: Extremely preterm $(<28$ weeks $\mathrm{GA})$

Very preterm $(28$ to $<32$ weeks GA)

Moderately preterm $(32$ to $<34$ weeks GA)

Late preterm (34 to $<37$ weeks GA)

Patient Characteristics and Outcome Measures

- Study assessments included patient characteristics and incidence of bronchopulmonary dysplasia (BPD) and chronic lung disease (CLD) among extremely preterm infants. HRU was assessed in extremely preterm

infants, and costs were assessed at 1- and 2-year corrected age (CA) after birth in all preterm infants.

- BPD was defined as requiring supplemental oxygen for either $>28$ days or by a diagnosis at 36 weeks post-menstrual age.

- CLD was defined as arising in the perinatal period and based on hospital admissions due to pulmonary causes and a pulmonary medication algorithm ( $\geq 1$ drug commonly prescribed for CLD in the Netherlands).

\section{RESULTS}

Study Cohort and Demographics

- The final study cohort included 6999 preterm infants, of whom 168 (2\%) were born extremely preterm (Figure 1).

- Infant and maternal characteristics of the population are summarised in the Table.

- BPD and CLD were reported in $40 \%$ and $29 \%$ of extremely preterm infants, respectively (data not displayed).

The proportion of infants with BPD at birth tended to increase with decreasing GA, from $29 \%$ (<28 weeks GA) to $64 \%$ (<25 weeks GA).

\section{Birth Hospitalisation}

- Median length of stay (LOS) of birth hospitalisation was 81 days (data not displayed), which was used to identify "short" (< median LOS) and "long" median LOS) birth hospitalisation.

- In the multi-variate regression analyses, low birth weight versus birth weight $\geq 1100 \mathrm{~g}$ was a significant predictor of long hospitalisation:

$<600 \mathrm{~g}$ (relative risk [RR], 2.83; $95 \% \mathrm{Cl}, 1.24-6.45$ )

700 to $<800 \mathrm{~g}$ (RR, 2.59; $95 \% \mathrm{Cl}, 1.15-5.81)$

800 to $<900 \mathrm{~g}$ (RR, 2.39; $95 \% \mathrm{Cl}, 1.07-5.36)$.

Hospital Readmissions

- Rates of all-cause and pulmonary-related hospital readmissions were highest in the period up to 1-year CA compared with 2-year CA for the overall population of extremely preterm infants and in the subgroups with and without BPD or CLD (Figure 2)

Costs of HRU

- On average, costs of birth hospitalisation summed up to $€ 126,350$ for extremely preterm infants. In the period up to 1- and 2-year CA, overal total HRU costs for extremely preterm infants, including hospitalisations and medication, summed up to $€ 10,500 /$ person-years (PY) and $€ 6700 / P Y$ respectively.

As expected, all costs across GA groups were higher at 1-year CA than 2-year CA, and were higher in infants with lower birth GA (Figure 3).

Figure 1. Flow Diagram Showing the Study Population Identified in the PHARMO Database Network With a Birth Record in the PRN and Data in the Out-patient Pharmacy and Hospitalisation Database

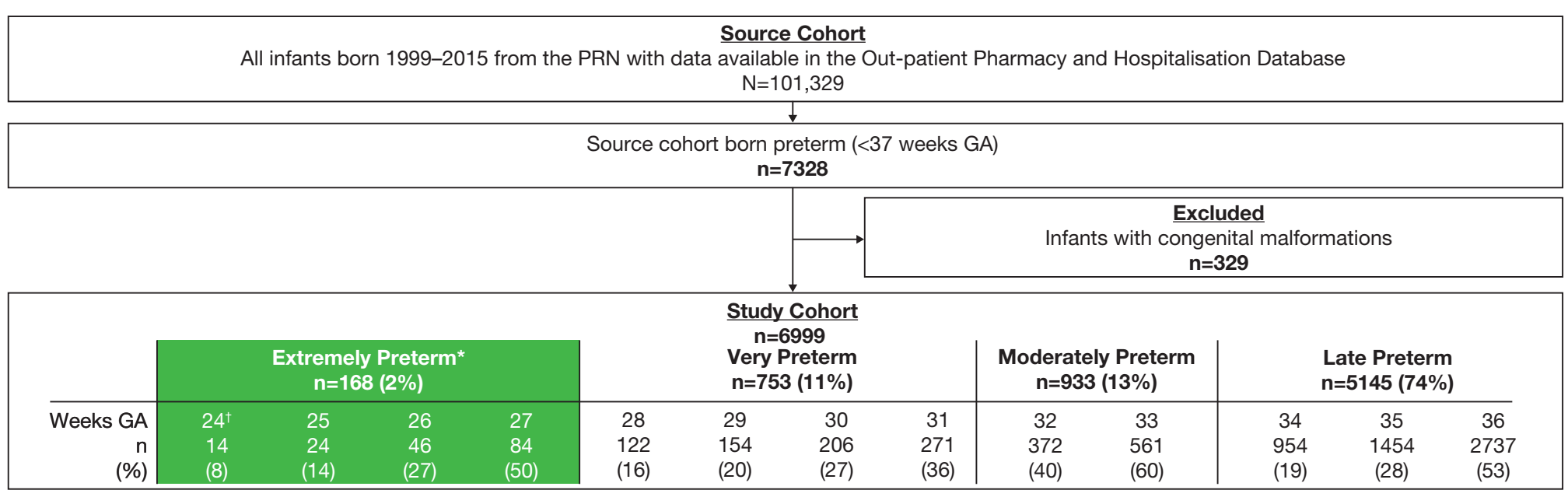

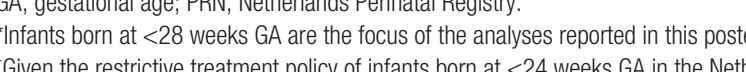

Table. Selected Infant and Maternal Characteristics at Birth by Morbidity Status of Infants Born at <28 Weeks GA in the PHARMO Database Network With a Birth Record in the PRN and Data in the Out-patient Pharmacy and Hospitalisation Database Between 1999-2015

\begin{tabular}{|c|c|c|c|c|c|}
\hline Status & $\begin{array}{l}\text { Overall } \\
\mathrm{N}=168\end{array}$ & $\begin{array}{c}\mathrm{BPD}^{*} \\
\mathrm{n}=67\end{array}$ & 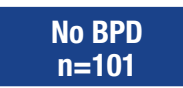 & $\begin{array}{c}\mathrm{CLD} \mathbf{D}^{+} \\
\mathrm{n}=49\end{array}$ & $\begin{array}{c}\text { No CLD } \\
n=119\end{array}$ \\
\hline $\begin{array}{l}\text { GA at birth, wk, } n(\%) \\
24 \\
25 \\
26 \\
27\end{array}$ & $\begin{array}{l}14(8) \\
24(14) \\
46(27) \\
84(50)\end{array}$ & $\begin{array}{l}9(13) \\
11(16) \\
23(34) \\
24(36)\end{array}$ & $\begin{array}{l}5(5) \\
13(13) \\
23(23) \\
60(59)\end{array}$ & $\begin{array}{l}4(8) \\
8(16) \\
18(37) \\
19(39)\end{array}$ & $\begin{array}{l}10(8) \\
16(13) \\
28(24) \\
65(55)\end{array}$ \\
\hline Male, $\mathrm{n}(\%)$ & $81(48)$ & $29(43)$ & $52(51)$ & $31(63)$ & $50(42)$ \\
\hline Median (IQR) birth weight, $g$ & $\begin{array}{c}900 \\
(743-1038)\end{array}$ & $\begin{array}{c}807 \\
(680-945)\end{array}$ & $\begin{array}{c}950 \\
(800-1080)\end{array}$ & $\begin{array}{c}874 \\
(720-1040)\end{array}$ & $\begin{array}{c}905 \\
(750-1035)\end{array}$ \\
\hline $\begin{array}{l}\text { 5-min Apgar score, n (\%) } \\
0-4 \\
5-7 \\
8 \\
9 \\
10\end{array}$ & $\begin{array}{l}8(5) \\
76(45) \\
41(24) \\
33(20) \\
10(6)\end{array}$ & $\begin{array}{c}4(6) \\
32(48) \\
18(27) \\
12(18) \\
1(1)\end{array}$ & $\begin{array}{c}4(4) \\
44(44) \\
23(23) \\
21(21) \\
9(9)\end{array}$ & $\begin{array}{c}3(6) \\
20(41) \\
14(29) \\
9(18) \\
3(6)\end{array}$ & $\begin{array}{c}5(4) \\
56(47) \\
27(23) \\
24(20) \\
7(6)\end{array}$ \\
\hline $\begin{array}{l}\text { Follow-up, years CA, } n(\%) \\
\geq 1 \\
\geq 2 \\
\text { Median (IQR) }\end{array}$ & $\begin{array}{c}152(90) \\
135(80) \\
5.0(2.6-8.1)\end{array}$ & $\begin{array}{c}59(88) \\
49(73) \\
3.5(1.9-6.9)\end{array}$ & $\begin{array}{c}93(92) \\
86(85) \\
5.3(3.8-8.9)\end{array}$ & $\begin{array}{c}45(92) \\
42(86) \\
6.6(4.2-10.0)\end{array}$ & $\begin{array}{c}107(90) \\
93(78) \\
4.4(2.1-7.1)\end{array}$ \\
\hline Mean (SD) mother's age at delivery, y & $31(5)$ & 30 (5) & $31(5)$ & $32(5)$ & $30(5)$ \\
\hline $\begin{array}{l}\text { Most frequent pregnancy risk factors, } n(\%) \\
\text { Prior preterm delivery } \\
\text { Hypertension } \\
\text { Antepartum haemorrhage }\end{array}$ & $\begin{array}{l}28(17) \\
21(13) \\
10(6)\end{array}$ & $\begin{array}{l}17(25) \\
10(15) \\
3(4)\end{array}$ & $\begin{array}{l}11(11) \\
11(11) \\
7(7)\end{array}$ & $\begin{array}{l}8(16) \\
5(10) \\
2(4)\end{array}$ & $\begin{array}{l}20(17) \\
16(13) \\
8(7)\end{array}$ \\
\hline
\end{tabular}

Figure 2. Frequency of Hospital Readmissions at 1- and 2-Year CA After Birth Among Extremely Preterm Infants in the PHARMO Database Network With a Birth Record in the PRN and Data in the Out-patient Pharmacy and Hospitalisation Database Between Database Neth

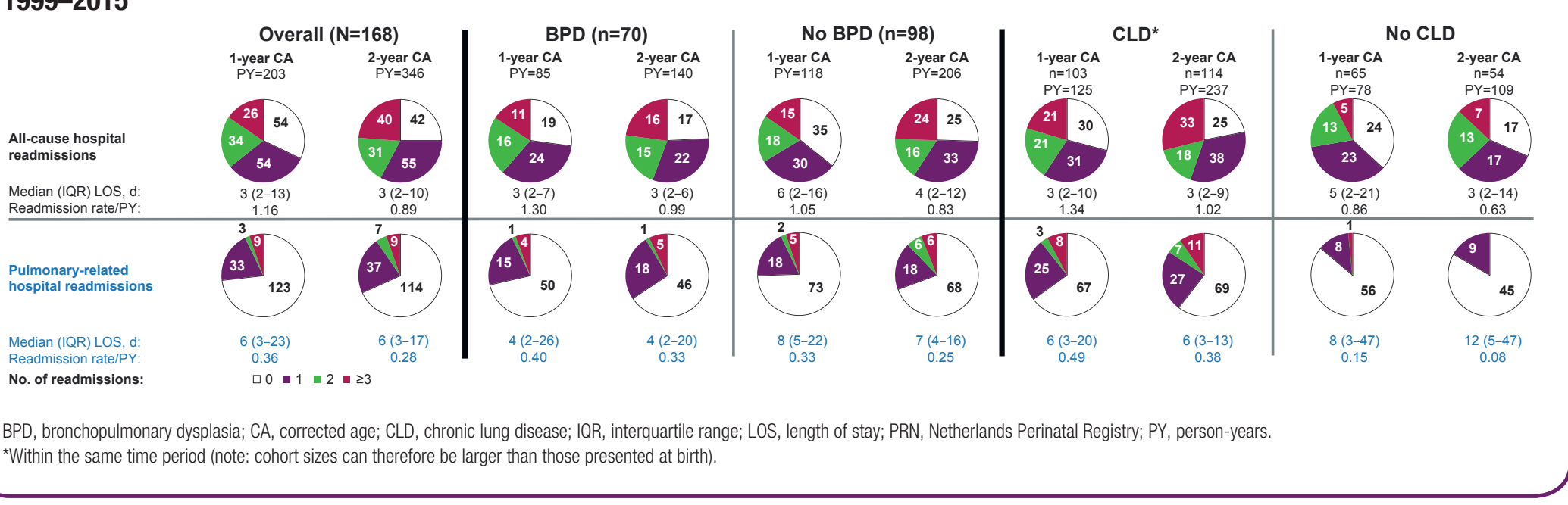

Figure 3. Costs of HRU $(x \in 1000 / P Y)^{*}$
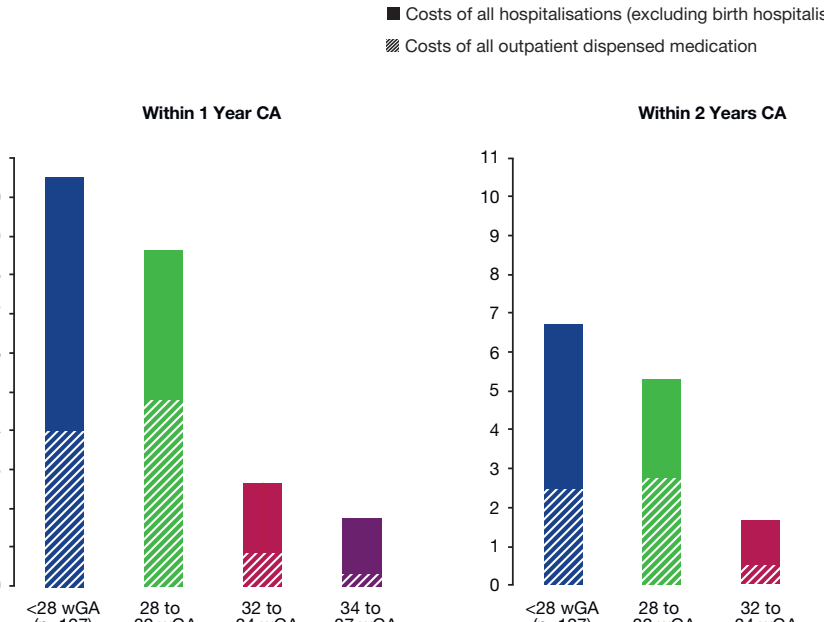

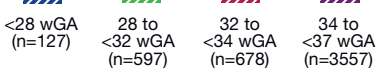

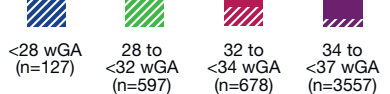

\section{CONCLUSIONS}

- Infants born at $<28$ weeks GA exhibit high prevalence of BPD and CLD at birth, and in particular, prevalence of BPD that increases substantially with decreasing GA.

- All-cause and pulmonary-related hospital readmission rates per person-year were higher among extremely preterm infants with than without BPD or CLD, and HRU costs were higher with lower GA.

- These data will help payers and clinicians plan and make informed treatment choices for infants born at $<28$ weeks GA, and provide a basis for future cost-effective analyses. 